\title{
A conciliar: \\ preparándose para una negociación asistida
}

Christian Stein Cárdenas

A partir de la entrada en vigencia de la Ley No $26872^{1}$, Ley de Conciliación (LC), como de su Reglamento (RG), aprobado por el Decreto Supremo $\mathrm{N}^{\circ}$ 001-98-JUS ${ }^{2}$, que junto con una serie de disposiciones finales, transitorias, complementarias, modificatorias, conexas y afines han servido para definir un marco normativo específico en virtud del cual se desarrolla hasta la fecha, a pesar de la postergación de la obligatoriedad de la conciliación como requisito de procedibilidad necesariamente previo a los procesos judiciales que detallaremos más adelante, operada mediante la Ley No $27218^{3}$, una serie de esfuerzos inconexos, tanto públicos como privados, por difundir y promover tan útil y eficiente mecanismo alternativo para la resolución de conflictos en nuestro país.

Algunos de los referidos esfuerzos nacieron destinados a un fin tan altruista como educar a la sociedad civil en la necesidad de un cambio que implique el tránsito de una mentalidad litigiosa hacia una mentalidad resolutiva, en busca del establecimiento de la denominada "cultura de paz» así como en el manejo de técnicas que coadyuven de manera simple, fácil y práctica a implementar herramientas concretas para lograr dicho objetivo; y otros dirigidos más bien a lucrar con la ilusión y candidez de aquellos que aplicando el sentido común y atendiendo a distintos niveles de sensibilidad, perciben que algo anda mal y que es

1 Promulgada el 29/10/97 y publicada en el Diario Oficial "El Peruano" el 13/11/97.

2 Promulgado el 13/01/98 y publicado en el Diario Oficial "El Peruano" el 14/01/98.

3 Promulgada el 09/12/99 y publicada en el Diario Oficial "El Peruano" el 12/12/97. 
hora de asumir algún tipo de compromiso, o simplemente como una posibilidad más de carácter profesional o laboral.

Este modesto escrito no tiene por finalidad ocuparse de la ya $\tan$ trillada, pero no por eso menos importante, crisis estructural que aqueja a nuestra sociedad en lo que a administración de justicia se refiere. Creemos de fundamental trascendencia el imperioso requerimiento de generar, sobre la base de un estudio serio y responsable tanto a nivel técnico como humano, una conciencia cívica acerca del rol que a cada uno de nosotros, letrados o no, sin distinción peyorativa alguna, nos toca jugar en el proceso coyuntural de cambio hacia nuestro propio futuro y el de aquellos que nos seguirán, juzgando y aprovechando nuestro legado, cumpliendo así con nuestra deuda histórica con aquellos que nos antecedieron, nos referimos a los que sentaron un precedente de amor digno y constancia en la entrega por sus ideales.

Tampoco pretendemos ocupar nuestros trabajos en entrar a presentar el esquema que, pensamos y sentimos, debe ser el que debe configurar la matriz curricular de los cursos de formación y capacitación de conciliadores que se imparten en los diferentes centro destinados para tales labores. Únicamente mencionaremos que, con el riesgo de caer en algunos detalles meramente técnicos, estamos convencidos de que un curso de tal naturaleza debe considerar, por lo menos, una revisión teórica de la naturaleza, características, dinámica y operatividad del proceso conciliatorio concebido como una negociación integrativa asistida, la descripción de herramientas neurolingǘsticas y su aplicación práctica dentro de un esquema estratégico racional en la orientación a la gestión del conflicto, teniendo como objetivos mínimos:

- Determinar las fases del proceso conciliatorio y las funciones que implica el rol del conciliador.

- Definir el perfil del conciliador y desarrollar habilidades y destrezas.

- Capacitar en la implementación del reporte de referentes sensoriales y en la elaboración de un análisis diagnóstico situacional del contexto conflictual, así como en la utilización de técnicas de comunicación cordial.

- Estimular la creatividad y el carácter ejecutivo del conciliador.

- Fomentar una cultura de paz, orden, estabilidad, seguridad, equidad y justicia sobre la base de un compromiso ético integral fundado en una orientación de carácter humanista de la actividad conciliatoria. 
Sin embargo, tenemos que mencionar que hemos interiorizado el deber de seguir ocupándonos responsablemente de los dos tópicos antes mencionados en la medida que nuestra capacidad y entendimiento nos lo permitan, asumiendo para esto nuestra mejor disposición, y en los foros y tribunas que nuestra disponibilidad, posibilidades y oportunidades nos consigan acceder.

Nuestra actual y ambiciosa meta, hacia la cual hemos orientado nuestros esfuerzos, es la de proponer ciertas ideas que sean aprovechables por los protagonistas olvidados de la conciliación: las partes. En efecto, la mayoría de intentos desplegados hasta ahora por promover la conciliación a nivel nacional están pretendidos para instruir a los conciliadores como directores de la audiencia de conciliación, desarrollando en ellos ciertas potencialidades que optimicen los resultados de la negociación que las partes deben llevar a cabo, definiendo un perfil idóneo para su tan loable misión. Muy pocos se han ocupado de quienes son los responsables tanto del proceso como del resultado de la gestión del conflicto: los conciliables.

Estamos de acuerdo en que para que el «mercado» de la conciliación funcione, es indispensable la formación y capacitación constante de excelentes multiplicadores o "proveedores de servicios", léase conciliadores. Pero también es fundamental que se fomente una «conciencia de consumo" que mediante una adecuada orientación y reeducación impulse a los miembros de la sociedad a ser excelentes «consumidores de servicios" de conciliación. Tanto la oferta como la demanda deben desarrollarse en paralelo.

Cabe acotar que las recomendaciones que plantearemos como pasos iniciales hacia una conciliación constituyen nuestro mejor consejo desde nuestra experiencia, tanto teórica como práctica, al momento de prepararnos como parte para conciliar, y deben complementarse con la estrategia que los asesores de los justiciables, sean abogados o no, deben seguir, siendo esto último de lo que nos ocuparemos en una próxima oportunidad.

\section{Conceptos preliminares: materias conciliables...}

En el artículo $9^{\circ}$ de la LC se establece: 
Artículo 9.- Materias Conciliables.- Son materia de conciliación las pretensiones determinadas o determinables que versen sobre derechos disponibles de las partes.

En asuntos relacionados al derecho de familia se someten al procedimiento establecido en la presente ley las pretensiones que versen sobre alimentos, régimen de visitas y violencia familiar. No se someten a Conciliación Extrajudicial las controversias sobre hechos que se refieran a la comisión de delitos o faltas, con excepción de las controversias relativas a la cuantía de la reparación civil derivada de la comisión de delitos, en cuanto ella no hubiera sido fijada por resolución judicial firme.

En este sentido, se estipula en el artículo $7^{\circ}, 9^{\circ}$ y $10^{\circ}$ del $R G$ lo siguiente:

Artículo 70.- De acuerdo con la Ley, la Conciliación puede ser:

\subsection{Por la iniciativa de las partes:}

\section{a) Obligatoria:}

Para los casos de derechos disponibles. Entiéndase por derechos disponibles aquellos que tienen un contenido patrimonial; es decir los que son susceptibles de ser valorados económicamente. Son también derechos disponibles aquellos que, no siendo necesariamente patrimoniales, pueden ser objeto de libre disposición.

De acuerdo con lo dispuesto en el Artículo $9^{\circ}$ de la Ley, y para efectos de la Conciliación, en los asuntos relativos a alimentos, régimen de visitas, violencia familiar y la responsabilidad civil proveniente de delito, sólo son conciliables los derechos de libre disposición.

La Conciliación en asuntos laborales supone el respeto de los derechos intangibles del trabajador, por lo que sólo opera en el ámbito de disponibilidad que éste disfruta."

b) Facultativa:

De acuerdo con lo establecido en el segundo párrafo del artículo $6^{\circ}$ de la Ley, cuando la parte emplazada domicilia en el extranjero y en los procesos cautelares, de ejecución y de garantías constitucionales. 
Cuando las partes han convenido que cualquier discrepancia entre ellas se solucionará en la vía arbitral. En este caso, las partes quedan habilitadas para iniciar inmediatamente el arbitraje.

\subsection{Por el resultado del trámite:}

a) Total:

Cuando las partes se han puesto de acuerdo respecto de todos los puntos relativos a su conflicto de intereses y señalados como tales en la solicitud de conciliación y a lo largo del procedimiento conciliatorio.

\section{b) Parcial:}

Cuando las partes se han puesto de acuerdo respecto de alguno o algunos de los puntos controvertidos, dejando otros sin resolver, o cuando exista acuerdo conciliatorio sólo entre algunos de ellos..."

Artículo $9^{\circ}$.- Para efectos de lo dispuesto en el artículo $9^{\circ}$ de la Ley, se entiende como pretensión determinada aquella por la cual se desea satisfacer un interés que ha sido perfectamente fijado en la solicitud de conciliación.

La pretensión es determinable cuando ésta es susceptible de fijarse con posterioridad a la presentación de la solicitud de conciliación.

No existe inconveniente para que, en el desarrollo de la conciliación, el conciliador y las partes den un contenido diferente a las pretensiones determinadas o determinables inicialmente previstas. En este caso, el acuerdo conciliatorio deberá referirse a éstas últimas.

Artículo 10.- Cuando la Ley menciona en su artículo $9{ }^{\circ}$ que son conciliables las pretensiones que versan sobre violencia familiar, debe entenderse que es posible sólo conciliar sobre los motivos o factores que generan la violencia, no siendo posible conciliar sobre la intensidad de la misma.

Debe tenerse en cuenta que, en estos casos, el fin de la conciliación es el cese definitivo de los actos de violencia, por lo que es nulo cualquier acuerdo que implique la renuncia de derechos o legitimen los actos de violencia.

Sobre el particular, debemos precisar el concepto de materias conciliables, para lo cual resulta indispensable, a diferencia de otros autores y a lo inorgánico de su trato tanto en la LC como en el RG, definir en primer lugar qué se entiende por derechos disponibles, acto 
seguido abordar la diferencia entre pretensiones determinadas y determinables, para finalmente tratar los casos de la diferida obligatoriedad de la conciliación preprocesal frente al beneficio de su facultatividad.

\section{Derechos disponibles}

Siendo plenamente concientes que toda definición es arbitraria y coincidiendo con Ormachea Choque ${ }^{4}$ en que la que nos ocupa presenta serias limitaciones respecto a la infinita casuística que produce la posibilidad de un sin número de interpretaciones y discusiones jurídicas sobre temas complejos, como por ejemplo, el de la patrimonialidad de la prestación dentro del terreno del derecho de las obligaciones, o las complicaciones naturales que se presentan en derecho administrativo y en derecho de familia, nos aventuramos a plantear ciertas inquietudes $e$ ideas que pueden ayudar a aclarar un poco el panorama sobre este punto, sin llegar a formular una definición por los motivos manifestados.

Según lo mencionado en el primer párrafo del literal a) del numeral 1. del artículo $7^{\circ}$ del RG, los derechos disponibles se dividen en patrimoniales y no patrimoniales. Los primeros son aquellos que tienen un contenido patrimonial y los segundos aquellos que sin ser «necesariamente» patrimoniales, pueden ser objeto de libre disposición. Al aludir al "contenido patrimonial" de los derechos disponibles se especifica que son los susceptibles de ser valorados económicamente. Encontramos inconveniente el hecho de condicionar la existencia de la categoría de derechos patrimoniales a la susceptibilidad de ser valorados económicamente, ya que, simplificando la relación de las partes conciliables en un sentido unidireccional para efectos didácticos, tanto el interés insatisfecho del «acreedor» como el sacrificio-esfuerzo que constituye la prestación entendida como conducta potencialmente debida a cargo del «deudor» en favor de la otra parte, pueden configurarse sobre la base de valoraciones relativa o absolutamente subjetivas, teniendo el aspecto económico poca o ninguna trascendencia.

4 Iván Ormachea Choque, Análisis de la Ley de Conciliación Extrajudicial Lima, Perú: Cultural Cuzco, 1998 , pp. 53-69. 
Asimismo, el incumplimiento de la aludida prestación por parte del deudor que generaría un proceso de ejecución posterior en su contra, y en su caso una final indemnización por daños y perjuicios en beneficio del acreedor, ésta última sí valorable económicamente en el sentido más claro que es el pecuniario, no debe inducir a pensar que los derechos materia de ese acuerdo incumplido son patrimoniales, ya que, recordando que todo acuerdo nace en teoría y puridad con vocación natural de cumplimiento, no se puede determinar la patrimonialidad de la prestación en función del antinatural incumplimiento (aspecto patológico) ya que si se hubiera cumplido no sería patrimonial.

En relación a los derechos que sin ser «necesariamente» patrimoniales pueden ser objeto de libre disposición, se alude a los temas de derecho de familia y de derecho penal en los segundo y tercer párrafos del artículo $9^{\circ}$ de la LC respectivamente, señalándose taxativamente a manera de numerus clausus a las materias de alimentos, régimen de visitas y violencia familiar en el primer caso y a la reparación civil proveniente de comisión de delitos, no fijada judicialmente, en el segundo. Se nota un esfuerzo por delimitar el universo de los derechos disponibles no patrimoniales. Sin embargo, al tratarse estos mismos temas en el segundo párrafo del artículo $7^{\circ} \mathrm{del} \mathrm{RG}$, se ratifica lo dicho en la LC y se añade que «[...] sólo son conciliables los derechos de libre disposición", cayendo en el mismo ambiguo entrampamiento conceptual, complementando esto con la incorporación en el tercer párrafo del mismo artículo, del tema del derecho laboral, haciendo mención que el límite del contenido negocial en éste ámbito lo constituye la disponibilidad de los derechos de los trabajadores, entendiendo nosotros éstos en atención a la irrenunciabilidad prescrita en el numeral 2 del artículo $26^{\circ}$ de la Constitución Política del Perú, del año 1993.

Cabe acotar que en la mayoría de los esquemas legales que incorporan a la conciliación como un mecanismo alternativo para la resolución de conflictos, ésta fue pensada primigeniamente para el ámbito civil y comercial, dispersando su influencia en otras áreas específicas frente a la necesidad de su especialización, producto de lo cual se desarrollaron una serie de reglas particulares de aplicación, la mismas que deben ser estudiadas para cada caso concreto.

No es nuestro propósito auscultar en este espacio todas las materias conciliables en lo familiar, penal, laboral, y contencioso administrativo, lo que debe ser objeto de un tratado especializado, procediendo noso- 
tros a sólo revisar muy someramente algunos conceptos a la luz de algunas anotaciones de derecho comparado, tomando como ejemplo a dos países hermanos en donde esta figura ha tenido notable desarrollo: Argentina y Colombia.

En el caso de la Ley No $24573^{5}$, Ley de Mediación y Conciliación de la Argentina, en sus artículos $2^{\circ}$ y $3^{\circ}$ se establece un sistema diferente al nuestro en parte (que presenta categorías abiertas para los derechos disponibles, lo cual implicará problemas de interpretación posteriores, $y$ «aparentemente" cerradas en lo que se refiere al tema de familia, por ejemplo, conforme hemos analizado) ya que se enumeran (categoría cerrada negativa) los asuntos en los cuales no cabe la conciliación:

Artículo $2^{\circ}$.- El procedimiento de la mediación (entiéndase Conciliación para todos sus efectos) obligatoria no será de aplicación en lo siguientes supuestos:

1. Causas penales.

2. Acciones de separación personal y divorcio, nulidad de matrimonio, filiación y patria potestad, con excepción de las cuestiones patrimoniales derivadas de éstas. El juez deberá dividir los procesos, derivando la parte patrimonial al mediador.

3. Procesos de declaración de incapacidad y de rehabilitación.

4. Causas en que el Estado nacional o sus entidades descentralizadas sean parte.

5. Amparo, hábeas corpus e interdictos.

6. Medidas cautelares hasta que se decidan las mismas, agotándose respecto de ellas las instancias recursivas ordinarias, continuando luego el trámite de la mediación.

7. Diligencias preliminares y prueba anticipada.

8. Juicios sucesorios y voluntarios.

9. Concursos preventivos y quiebras.

10. Causas que tramiten ante la justicia nacional del trabajo. 
Artículo $3^{\circ}$.- En el caso de los procesos de ejecución y juicios de desalojo, el presente régimen de mediación será optativo para el reclamante, debiendo en dicho supuesto el requerido ocurrir a tal instancia."

Adicionalmente, en el Decreto $N^{\circ} 91 / 98^{6}$, Reglamentación de la Ley No 24573 de Mediación Obligatoria, se prescribe en su artículo $2^{\circ}$ las excepciones a la inaplicabilidad de la mediación:

Artículo $2^{\circ}$.- Excepciones a la inaplicabilidad de la mediación. Cuando se inicie alguna de las acciones previstas en el artículo $2^{\circ}$, inciso 2 de la Ley No 24573 que contenga las cuestiones patrimoniales mencionadas en esa disposición, el actor debe impulsar el trámite de mediación respecto de estas últimas y dejar constancia en el expediente principal.

Cuando en los juicios sucesorios se suscitaren cuestiones controvertidas en materia patrimonial, a pedido de parte se las podrá derivar al mediador que se sortee o que designen por elección las partes interesadas.

En Colombia, en virtud de lo dispuesto en el artículo $2^{\circ}$ del Decreto No 1818 de 1998, compilación de las normas aplicables a la conciliación, al arbitraje, a la amigable composición y a la conciliación en equidad denominado Estatuto de los Mecanismos Alternativos de Solución de Conflictos se dice:

Artículo $2^{\circ}$.- Asuntos conciliables. Serán conciliables todos los asuntos susceptibes de transacción, desestimiento y aquellos que expresamente determine la ley (artículo 65 Ley No 446 de 1998).

Sobre la base de esta concepción, Varón Palomino ${ }^{7}$ realiza el siguiente análisis descriptivo:

Para que un conflicto de naturaleza civil o comercial pueda resolverse a través de conciliación, debe reunir tres requisitos generales, a saber:

6 Bs. As.: 26/01/98; B.O.: 29/01/98.

7 Juan Carlos Varóno Palomino, La Conciliación en el Derecho Civil. Santafé de Bogotá, D.C., Colombia: Interconed, 1996, pp. 24-25. 
- Que se trate de un conflicto de naturaleza patrimonial (contenido económico) o extrapatrimonial, originado en alguna de las fuentes de las obligaciones civiles o mercantiles - la ley, el negocio jurídico, el acto jurídico, el daño-, etc;

- Que la controversia sea susceptible de transacción, vale decir, que verse sobre asuntos y derechos sobre los cuales las partes tengan poder de disposición;

- Que no exista prohibición legal de transar o conciliar en el tema considerado.

Así las cosas, entre las materias conciliables en las áreas que nos ocupan pueden mencionarse las siguientes:

$1^{\text {a. }}$ Disputas patrimoniales relativas a los modos de adquirir el dominio, el uso, goce y posesión de los bienes, servidumbre y gravámenes al dominio, excepto en lo relativo a la validez de la tradición.

$2^{\text {a }}$. Conflictos económicos sobre empresas y establecimientos de comercio.

$3^{a}$. Disputas patrimoniales relativas a la celebración, ejecución y terminación de los contratos civiles y comerciales, tales como compraventa, permuta, arrendamiento, mutuo, mandato, depósito, dación en pago, prestación de servicios, fiducia, leasing, contrato bancarios, agencia, comisión, seguro, corretaje, preposición, prendas, hipotecas, y cesión de derechos.

$4^{a}$. Disputas económicas derivadas de la creación y negociación de títulos valores de contenido crediticio, de participación y de tradición o representativos de mercaderías, así como aquellas relativas al cumplimiento de obligaciones incorporadas en tales instrumentos.

$5^{a}$. Disputas de carácter patrimonial referentes a la constitución, extinción y liquidación de sociedades civiles, comerciales y de hecho: aportes, pago de utilidades, pago de pasivos y distribución de bienes en la liquidación.

6a. Disputas de carácter patrimonial referentes a propiedad industrial marcas y patentes-.

$7^{\text {a }}$. Disputas patrimoniales surgidas en el marco de procesos de concordato, quiebra o liquidación de sociedades. 
A contrario sensu, no son conciliables las diferencias que versen sobre temas civiles o comerciales respecto de los cuales las partes no tienen capacidad de transacción.

En este orden de ideas, quedan excluidos de la posibilidad de conciliación los siguientes asuntos:

$1^{\circ}$. El nombre, el estado civil, la capacidad e incapacidad y la nacionalidad de las personas -sin perjuicio del derecho constitucional de optar por varias nacionalidades o renunciar a ellas-.

$2^{\circ}$. Las solemnidades sustanciales exigidas por la ley para la formación de ciertos actos o contratos.

$3^{\circ}$. La calidad de comerciante y sus obligaciones profesionales.

$4^{\circ}$. La eficacia probatoria de los libros de comercio.

$5^{\circ}$. La validez o nulidad de actos que generen obligaciones civiles o mercantiles.

$6^{\circ}$. La calidad de heredero o legatario, las asignaciones testamentarias forzosas, y las disposiciones de un testamento legalmente constituido.

Concordante con el reseñado análisis, el mismo Varón Palomino ${ }^{8}$ complementa la definición de Conciliación elaborada con Pérez Villareal ${ }^{9}$, sosteniendo la noción, habiendo nosotros coordinado ambos textos, de un trámite a través del cual dos o más partes en conflicto buscan solucionar sus diferencias transigibles, con la ayuda de un tercero neutral llamado conciliador, mediante la búsqueda de acuerdos lícitos, equitativos y de mutuo beneficio, siendo su elemento objetivo "El conflicto cuya solución se pretende debe ser susceptible de transacción».

De lo expuesto se aprecia que en los dos sistemas jurídicos latinoamericanos que han nutrido principalmente al nuestro en lo que a la estructuración orgánica de la institución conciliatoria se refiere, se mantiene la tendencia de "patrimonializar» los derechos disponibles, incurriendo en el error ya acotado por nosotros.

8 Op. Cit., p. 15.

9 María Luzsabel Pérez Villareal y Juan Carlos Varón Palomino, Técnicas de Conciliación. Santafé de Bogotá, D.C., Colombia: Programa de Modernización de la Administración de Justicia FES - AID, 1996, p.13. 
No obstante lo anterior, pensamos que resulta bastante conveniente para salvar este impasse, empezar por centrar el tema. En el artículo $3^{\circ}$ de la LC se enuncia que:

Artículo $3^{\circ}$.- Autonomía de la Voluntad. La Conciliación es una institución consensual, en tal sentido los acuerdos adoptados obedecen única y exclusivamente a la voluntad de las partes.

En el artículo $5^{\circ}$ de la LC se refuerza el carácter institucional de la conciliación, así como la idea de la condición de consensual que debe tener la solución del conflicto sometido a ella.

En la misma línea, en los artículos $3^{\circ}$ y $4^{\circ}$ del RG se indica respectivamente que «La Conciliación es el acto jurídico [...] Se funda en el principio de la autonomía de la voluntad», y que «El acuerdo conciliatorio es fiel expresión de la voluntad de las partes y del consenso al que han llegado para solucionar sus diferencias $[. .$.$] "$

Un acierto consideramos lo consignado en el artículo $5^{\circ}$ del RG en el sentido de que:

Artículo $5^{\circ}$.- La autonomía de la voluntad a que hace referencia el Artículo $3^{\circ}$ de la Ley, no se ejerce irrestrictamente. Las partes pueden disponer de sus derechos siempre y cuando no afecten con ello normas de carácter imperativo ni contrarien el orden público ni las buenas costumbres.

De la misma forma que en la LG, en el artículo $6^{\circ}$ del RG se respalda que lo que busca la conciliación es una solución consensual al conflicto.

A nuestro entender, la conciliación es una institución cuyo noble destino, y deseable y pretendida manifestación última es una acto jurídico, pero que no necesariamente culmina así, ya que se puede llevar a cabo todo el proceso conciliatorio siguiendo los principios que la inspiran y el cauce de las disposiciones procedimentales prescritas en sus normas reguladoras, sin finiquitarlo con acuerdo alguno, sea éste parcial o total.

La conciliación es una institución, no asimilándola restrictivamente con criterios jurídicos sino entendiéndola extensivamente, porque posee una lógica propia derivada de un desarrollo histórico en diferentes 
contextos temporales y espaciales, y porque constituye una "colección metódica de los principios de una ciencia, arte, etc.» y tiene «el prestigio debido a la antigüedad o a poseer todos los caracteres representativos de aquella. " ${ }^{10}$

Así también, la conciliación es potencialmente un acto jurídico, el cual se va configurando progresivamente durante el proceso. No olvidemos que la conciliación, operativamente hablando, no es más que una negociación integrativa (participativa, colaborativa, etc.) asistida por un tercero, y que se perfecciona si al final de ésta existe un acuerdo de cualquier naturaleza entre las partes, es decir, al darse por lo menos una coincidencia de voluntades entre los conciliables respecto a sus diferencias, la que será plasmada en un documento solemne denominado Acta de Conciliación, el mismo que conforme a lo anotado en los artículos $16^{\circ}$ de la LC y $24^{\circ}$ del RG: "[...] expresa la voluntad de las partes en la Conciliación [...]", constituyendo el acuerdo conciliatorio según lo dispuesto en el artículo $18^{\circ}$ de la LC, Título de Ejecución, siendo los derechos, deberes u obligaciones ciertos, expresos y exigibles que en el Acta consten, exigibles a través del proceso de ejecución de resoluciones judiciales descrito en el Código Procesal Civil de 1992.

En nuestro ordenamiento jurídico, no nos sirve de mucho hacer coincidir a los derechos disponibles con los transigibles, ya que, si bien lo contenido en los artículos $1302^{\circ}$ al $1312^{\circ}$ del Código Civil, pertenecientes al Título VII «Transacción" de la Sección Segunda "Efectos de las Obligaciones» del Libro VI «Las Obligaciones», se asemeja en mucho a lo regulado en las normas sobre Conciliación, lamentablemente se parece demasiado en el artículo $1305^{\circ}$ cuando se coloca que:

Artículo $1305^{\circ}$.- Sólo los derechos patrimoniales pueden ser objeto de transacción."

Todo lo cual nos lleva a concluir que no resulta conveniente clasificar a los derechos disponibles en patrimoniales o no patrimoniales, ya que como hemos visto, la patrimonialidad no es un criterio diferenciador válido ni legítimo, debido a los problemas que su presencia conlleva, ya comentados por nosotros.

10 Diccionario de la Lengua Española, Madrid, España, Espasa-Calpe, vigésima edición, 1984 , p. 778. 
Entonces, en nuestra opinión encontramos adecuado, a efecto de conceptuar los derechos disponibles sin "patrimonializarlos" y por ende acarrear todas las dificultades que ello involucra, el rescatar de la definición de conciliación de Varón Palomino y Pérez Villareal ${ }^{11}$ sobre todo el elemento licitud, fuera de la equidad y el mutuo beneficio; junto con la idea de la conciliación como institución consensual evidenciada en los artículos $3^{\circ}$ y $5^{\circ}$ de la LC, y como acto jurídico fundado en el principio de la autonomía de la voluntad, siendo el acuerdo conciliatorio fiel expresión de la voluntad de las partes y del consenso al que han llegado para solucionar su diferencias, en los artículos $3^{\circ} \mathrm{y}$ $4^{\circ}$ del RG; además de concordar en que lo que busca la conciliación es también una solución consensual al conflicto, siguiendo a lo dicho en el artículo $6^{\circ}$ del RG; así como revalorar y resaltar lo reseñado en el artículo $5^{\circ}$ del RG al imponer como límites a la autonomía de la voluntad tratada, la no afectación de las normas de carácter imperativo, del orden público y de las buenas costumbres.

Concluyendo, somos de la idea de determinar la existencia y clasificación de la categoría de los derechos disponibles no por su patrimonialidad como indebidamente se viene haciendo, sino más bien en función a los parámetros impuestos a la capacidad discrecional de los conciliables por el propio ordenamiento jurídico; en otras palabras, hablemos de derechos disponibles o indisponibles en razón ya sea de su particular naturaleza o de la «voluntad» de la ley, pudiendo ejercer las partes una restricta autonomía de la voluntad de conformidad con las normas que internen mandatos de estricto cumplimiento, tales como las contenidas en los artículos $140^{\circ}$ y $141^{\circ}$ parte del Título I «Disposiciones Generales" del Libro II "Acto Jurídico" del Código Civil de 1984, las mismas que encontramos perfectamente aplicables al considerar nosotros a la conciliación, cuando termina en acuerdo sea cual fuere su clase, como una fuente más de obligaciones, pudiendo complementarse con una analogía con los artículos $1402^{\circ}$ y $1403^{\circ}$ pertenecientes al Título Tercero "Objeto del Contrato" de la Sección Primera "Contratos en General» del Libro VII "Fuentes de las Obligaciones" del mismo cuerpo legal. 


\section{Pretensiones determinadas y determinables}

Sin mucho que completar, acordando con lo escrito en los artículos $9^{\circ}$ de la LC y $9^{\circ}$ del RG, diremos que las pretensiones son determinadas cuando con ellas se busca satisfacer un interés que ha sido perfectamente fijado en la solicitud de conciliación.

Por el contrario, serán pretensiones determinables aquellas que son susceptibles de fijarse con posterioridad a la presentación de la solicitud de conciliación.

Una de las riquezas de la conciliación, adicionalmente a su carácter multidisciplinario, radica en su flexibilidad a nivel procesal, gracias a la cual las partes con la asistencia del conciliador, pueden durante el desarrollo de la conciliación, variar las pretensiones determinadas o determinables que motivaron formalmente la conciliación, debiendo el acuerdo conciliatorio referirse a ellas.

\subsection{Obligatoriedad vs. Facultatividad}

En los artículos $6^{\circ}$ de la LG y $7^{\circ}$ del RG se instaura a la conciliación como un requisito de procedibilidad (aunque en la propia Ley se le menciona como de admisibilidad en la sexta disposición transitoria) necesariamente previo a los procesos judiciales que hemos revisado en el artículo $9^{\circ}$ de la LG, en otras palabras, respecto de las pretensiones determinadas o determinables que versen sobre derechos disponibles de las partes.

Como hemos mencionado al inicio de este ensayo, este carácter obligatorio en los casos precedentes ha sido diferido hasta el 14 de enero del año 2001 por lo ordenado en la Ley No 27218, siendo la conciliación hasta este momento, facultativa para todos los supuestos contenidos en la LC y el RG.

La conciliación se presenta como facultativa cuando la parte emplazada domicilia en el extranjero, en los procesos cautelares, de ejecución y de garantías constitucionales; y ante la existencia de un convenio arbitral, no existiendo limitación formal alguna para que las partes accedan a la instancia arbitral reconocida como jurisdicción especial. Sobre este punto, existen discrepancias que serán objeto de otras publicaciones. 
IV. Consideraciones generales: antes de conciliar...

\subsection{Determinación de intereses}

Frente a una situación potencial o real de conflicto, las partes involucradas van a presentarse mutuamente, y al conciliador también, lo que hemos denominado «la vitrina del conflicto», dado que es lo más visible y lo percibible de primera impresión, constituida por las posiciones de las partes, planteadas como las soluciones primarias al conflicto. Las posiciones están conformadas por los requerimientos, exigencias, demandas y argumentos propuestos inicialmente por los conciliables respecto a la controversia. Las posiciones son lo que aparentemente quieren los protagonistas del problema. Se puede decir que una posición es solamente un modo de satisfacer un interés.

Por contraposición, abajo, subyaciendo a las posiciones se encuentra lo que se puede llamar la "agenda oculta», la «información esotérica" o el "valor agregado" del conflicto, constituido por los verdaderos intereses de las partes, planteados como las razones por las cuales las partes plantearon a su vez sus soluciones primarias al conflicto. Los intereses están conformados por los sentimientos, necesidades, deseos y peticiones (condicionales) de los conciliables respecto a la controversia. Los intereses son lo que realmente quieren los protagonistas del problema. También se pueden definir como «[...] las necesidades, preocupaciones, metas, motivos y esperanzas que lo motivan a Ud. a negociar. " ${ }^{12}$

Antes de participar como parte en una conciliación, recomendamos llevar a cabo un "proceso de exploración de intereses" personal, preguntándose a uno mismo primero ¿qué es lo que quiero? y luego ¿para qué lo quiero, qué pretendo con eso, cual es la causa por la que lo quiero, qué quiero conseguir realmente de esta situación o de esta persona? Posteriormente se debe realizar preguntas como ¿qué o cómo me siento con todo esto?, ¿qué necesito de esta situación o de esta persona?, ¿qué deseo en realidad, qué me gustaría seriamente, sin caprichos, resentimientos u orgullo? y ¿qué le pediría a la otra parte de forma que mejore nuestra relación o por lo menos que no la empeore?

12 Julio Decaro y Mark Smith, Formación de Formadores, Nivel I, 28 de octubre -1 de noviembre de 1996, Lima, Perú, Lima, Perú: Conflict Management, 1996, módulo 7, p. 15. 
El "proceso de exploración de intereses» personal tiene por función permitir el autoconocimiento de los propios intereses, el ulterior conocimiento recíproco de éstos por las partes del conflicto y determinar la función de éste para cada una, estimulando la flexibilización desde las posiciones hacia los intereses, buscando involucrarlos en un proyecto conjunto de solución, desvirtuando un enfrentamiento entre ambas partes e induciendo a un enfrentamiento de ellos juntos contra el conflicto. Se estimula de esta manera el trabajo en equipo, que implica un grupo de personas con un objetivo y compromiso comunes.

Acto seguido, es útil efectuar un «análisis costo beneficio» individual, estudiando dos variables: las necesidades, y la existencia y disponibilidad de recursos, ambas tanto presentes (actuales) como futuras (proyectadas), con el propósito de tomar conciencia de la correspondencia entre nuestras legítimas "aspiraciones" y nuestra real capacidad de «inversión», esbozando nuestro margen de negociación.

No hay que olvidar que la conciliación no es otra cosa que una negociación integrativa (participativa, colaborativa, con base en principios, racional, etc.) asistida por un tercero que es el conciliador. Por lo tanto, la orientación que se le debe dar a la gestión del conflicto, sea esta preventiva o administrativa, debe ser negocial (estratégico racional), sobre cuya se debe implementar un esquema positivo ganar-ganar, en virtud del cual, las partes atiendan a sus verdaderos intereses en mutuo beneficio, considerando a las concesiones recíprocas como actos de colaboración, y no como sacrificios, pérdidas o renuncias fruto del estéril, impersonal y polarizante regateo, estrategia ésta última de la negociación distributiva basada en un esquema negativo ganar-perder ("suma cero"), por el cual cada parte evalúa egoistamente su éxito en función al sacrificio de la otra.

Acierta $\mathrm{Ury}^{13}$ al describir que: «Típicamente, la negociación comienza cuando la posición de una parte entra en conflicto con la posición de la otra parte. En el regateo corriente, tal vez lo único que usted necesita saber de antemano es su propia posición; pero la solución conjunta de problemas depende de los intereses subyacentes en la posición de cada parte. La diferencia es fundamental: la posición de usted son las cosas concretas que desea - los dólares y los centavos, los plazos y las condiciones. Los intereses de usted son las motivaciones intangibles que lo

13 William Ury, ¡Supere el NO!, Bogotá, Colombia, Norma, 1993, p. 15. 
llevan a asumir esa posición - sus necesidades, deseos, preocupaciones, temores y aspiraciones. Para poder llegar a un acuerdo satisfactorio para ambas partes, tiene que comenzar por descifrar los intereses de ambas partes."

\subsection{Generando alternativas}

Las alternativas son las vías individuales de satisfacción de intereses que tiene cada parte en el caso de no llegar a un acuerdo con la otra, independientemente de la voluntad de ésta. Obviamente, si como consecuencia del proceso conciliatorio alguna parte no ha cubierto sus expectativas, ésta no querrá llegar a ningún acuerdo. Entonces, no puede permitirse dejar a sus intereses «vacíos» o «en blanco» teniendo que agenciarse una vez frustrada la negociación, ya por cuenta propia, con la colaboración de terceros o no, alguna forma de satisfacer su intereses pendientes.

Se tiene que definir y desarrollar las alternativas antes de iniciar la conciliación, ya que esto le da a la parte más poder de negociación, el mismo que depende de la posibilidad de cada parte de abandonar la conciliación, más "palanca», más seguridad y minimiza o hasta elimina el miedo a la frustración, permitiendo protegerse de resultados negativos y tener mayor soltura y tranquilidad para generar y proponer opciones de solución creativas y originales a la otra parte, y que sean realmente en mutuo beneficio. El saber cuales son sus alternativas antes de la conciliación le otorga a cada parte la posibilidad de presentar sus intereses con más fuerza.

Dentro de la gama de alternativas que cada parte se plantea, cada una debe escoger la que de mejor manera y en mayor medida satisface sus intereses, los "llena" más, determinando así su MAAN ${ }^{14}$ (Mejor Alternativa a un Acuerdo Negociado), también nombrado como MAPAN $^{15}$ (Mejor Alternativa Para un Acuerdo Negociado) o MAFAN ${ }^{16}$ (Mejor Acuerdo a la Frustración de un Acuerdo Negociado). El MAAN

14 Roger Fisher, William Ury y Bruce Patton, Sí... De Acuerdo!, Santafé de Bogotá, D.C., Colombia: Norma, 1981, p. 120 ss.

15 William Ury, ¡Supere el NO!, Bogotá, Colombia, Norma, 1993, pp. 19 y ss.

16 Iván Ormachea Choque, Manual de Conciliación, Lima, Perú: Iprecom, 1999 p. 53. 
establece el "límite del sacrificio" de cada parte. Ninguna de ellas debe acordar algo con la otra que sea inferior al MAAN de aquella.

Estamos de acuerdo con Fisher, Ury y Patton ${ }^{17}$ cuando sostienen que: «La razón para negociar es obtener algo mejor de lo que se obtendría sin negociar». ¿Cuáles son esos resultados? ¿Cuál es su MAAN: su mejor alternativa para negociar un acuerdo? Ese es el criterio con el que se debe juzgar cualquier propuesta. Ese es el único criterio que puede protegerlo de aceptar términos demasiado desfavorables y de rechazar términos que le sería conveniente aceptar.

Su MAAN no es solamente un mejor criterio, sino que tiene la ventaja de ser lo suficientemente flexible como para permitirle explorar soluciones imaginativas. En vez de rechazar cualquier solución que no se ajusta a su mínimo, usted puede comparar una propuesta con su MAAN y ver si satisface mejor sus intereses."

Coincidimos plenamente con URY ${ }^{18}$ cuando afirma que: «Muy frecuentemente, la gente entra en una negociación en busca de un acuerdo, y estudia las alternativas solamente si las cosas van mal. Esto es un clásico error. Si usted sabe cuáles son sus alternativas, ello puede determinar su éxito en satisfacer sus intereses [...] El propósito de la negociación no siempre es llegar a un acuerdo. Porque acuerdo es sólo un medio, y el fin es satisfacer los intereses de usted. El propósito de la negociación es explorar si usted puede satisfacer mejor sus intereses por medio de un acuerdo que por medio de su mejor alternativa para un acuerdo negociado (MAPAN) [...] La MAPAN es la clave del poder de negociación. El poder de usted no depende tanto de que usted sea más grande, más fuerte, de mayor jerarquía o más rico que la otra persona, como de cuán bueno sea su MAPAN. Si usted tiene una alternativa viable, usted lleva una ventaja en la negociación. Cuando mejor sea su MAPAN, más poder tendrá usted [...] No suele existir ya un MAPAN; hay que desarrollarla. Si su MAPAN no es muy sólida, usted debe tomar medidas para mejorarla."

Es importante aprender a no confundir a las alternativas con las opciones, ya que éstas últimas son las vías conjuntas de satisfacción de intereses que cada parte le propone a la otra a efecto de lograr desarro- 
llar una acuerdo lícito, equitativo y de mutuo beneficio. Constituyen las propuestas concretas que cada parte le propone a la otra para resolver el conflicto, son las fórmulas conciliatorias que cada conciliable plantea durante la conciliación. Para Decaro y Smith ${ }^{19}$ : «Las opciones son todas las posibilidades en las cuales los partidos pueden concebiblemente llegar a un compromiso".

\section{Alcances complementarios: A saber...}

A continuación presentamos nuestra idea de lo que significa la Conciliación:

Conciliación ${ }^{20}$ Mecanismo Alternativo para la Resolución de Conflictos (MARC) consistente en una negociación integrativa asistida, configurándose en un proceso mediante el cual, las partes involucradas en un conflicto cuyos intereses versen sobre derechos disponibles, acceden voluntariamente a permitir la intervención de un tercero (técnico e imparcial y con capacidad de proponer fórmulas conciliatorias) que sirve de facilitador entre ellas, en el logro de una solución concertada. La función de dicho tercero es la de estimular la dinámica de la estructura del sistema comunicativo entre las partes, utilizando herramientas del lenguaje que le permitan aclarar percepciones y compatibilizar criterios de legitimidad sobre la base de un manejo racional de la información; debe lograr romper el juego de posiciones, flexibilizándolas centrando a las partes en sus verdaderos intereses, buscando separar a las personas del conflicto y enfrentarlas a él, cambiando los conceptos de "problema" por "proyecto de solución", "competencia" por "cooperación" y «discusión" por

19 Op. Cit, p. 17.

20 Christian Stein, "Mecanismos Alternativos para la Resolución de Conflictos y Técnicas de Negociación y Conciliación", materiales del Primer Curso Taller de Capacitación y Formación de Conciliadores en Mecanismos Alternativos para la Resolución de Conflictos y Técnicas de Negociación y Conciliación, Ministerio de Justicia, Agencia para el Desarrollo Internacional de los Estados Unidos de Norteamérica - USAID -, Cámara de Comercio de Lima, para el personal asignado a los Consultorios Jurídicos Populares (Convenio MINJUS USAID), Lima, abril 1998. 
«diálogo», siendo los mismos involucrados los que sobre la base de principios y creatividad en la generación de opciones vinculantes de solución y alternativas individuales de satisfacción de intereses, lleguen a resolver su propio conflicto, mediante la asunción de un compromiso contenido en el acuerdo construido en función a confianza, que de concretarse aquél, optimice la relación existente en virtud de la interdependencia generada entre ellas. 